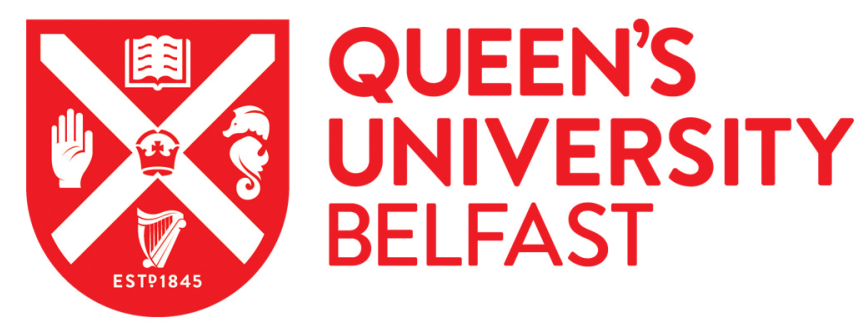

\title{
Prognosis following surgical resection versus local excision of stage pT1 colorectal cancer: a population-based cohort study: Surgical resection versus local excision for pT1 colorectal cancer
}

McBride, R., Hicks, B., Coleman, H., Loughrey, M. B., Gavin, A., Dunne, P., \& Campbell, W. J. (2019).

Prognosis following surgical resection versus local excision of stage pT1 colorectal cancer: a population-based cohort study: Surgical resection versus local excision for pT1 colorectal cancer. Surgeon-Journal of the royal colleges of surgeons of edinburgh and ireland. https://doi.org/10.1016/j.surge.2019.06.004

\section{Published in:}

Surgeon-Journal of the royal colleges of surgeons of edinburgh and ireland

\section{Document Version:}

Peer reviewed version

Queen's University Belfast - Research Portal:

Link to publication record in Queen's University Belfast Research Portal

\section{Publisher rights}

Copyright 2019 Elsevier.

This manuscript is distributed under a Creative Commons Attribution-NonCommercial-NoDerivs License

(https://creativecommons.org/licenses/by-nc-nd/4.0/), which permits distribution and reproduction for non-commercial purposes, provided the author and source are cited.

\section{General rights}

Copyright for the publications made accessible via the Queen's University Belfast Research Portal is retained by the author(s) and / or other copyright owners and it is a condition of accessing these publications that users recognise and abide by the legal requirements associated with these rights.

Take down policy

The Research Portal is Queen's institutional repository that provides access to Queen's research output. Every effort has been made to ensure that content in the Research Portal does not infringe any person's rights, or applicable UK laws. If you discover content in the

Research Portal that you believe breaches copyright or violates any law, please contact openaccess@qub.ac.uk. 


\section{Prognosis following surgical resection versus local excision of stage pT1 colorectal cancer: a population-based cohort study}

Running title: Surgical resection versus local excision for pT1 colorectal cancer

Rachael McBride ${ }^{a}$, Blanaid M. Hicks ${ }^{b}$, Helen G. Coleman ${ }^{b, c}$, Maurice B. Loughrey, ${ }^{a, b}$ Anna T. Gavin $^{d}$, Philip D. Dunnec, W. Jeffrey Campbell e

${ }^{a}$ Belfast Health and Social Care Trust, Belfast, Northern Ireland

${ }^{b}$ Centre for Public Health, Queen's University Belfast, Belfast, Northern Ireland

'Centre for Cancer Research and Cell Biology, Queen's University Belfast, Belfast, Northern Ireland

${ }^{\mathrm{d}}$ Northern Ireland Cancer Registry, Belfast, Northern Ireland

e South Eastern Health and Social Care Trust, Ulster Hospital, Dundonald, Northern Ireland

Funding: No funding source

Article type: original article

Keywords: colon cancer; rectal cancer; surgery; epidemiology; treatment. 


\section{Abstract}

\section{Abstract}

Aims: To evaluate patient management following stage pT1 colorectal cancer (CRC) diagnosis, and to determine if surgical resection improved outcome compared with local excision, within a population-based study.

Methods: Data were collected from the Northern Ireland Cancer Registry. Cases of stage pT1 CRC diagnosed from 2007 to 2012 were identified. Analyses were conducted using Cox proportional hazard models to calculate hazard ratios (HR) and $95 \%$ confidence intervals $(\mathrm{Cl})$ for cancer-specific and all-cause mortality for individuals undergoing formal surgery versus local excision.

Results: 394 patients with pT1 CRC were included. Of these, $37.1 \%$ were treated by local resection, $36.8 \%$ had biopsy followed by surgery and $26.1 \%$ had local excision followed by surgery. There were 60 deaths over a mean 4.8 years of follow-up, including 10 CRC-specific deaths. An additional 12 patients had a CRC recurrence or metastases during follow-up. Of the CRC-specific deaths or recurrences, $27.3 \%$ had local excision only. Individuals treated by formal surgery did not have a reduced risk of CRC-specific death (adjusted $\mathrm{HR}=1.51,95 \% \mathrm{Cl}$ $0.29,7.89$ ), but did have a reduced risk of all-cause mortality (adjusted $\mathrm{HR}=0.5195 \% \mathrm{Cl} 0.30$, 0.87) compared with those undergoing local excision only.

Conclusions: Patients with stage PT1 CRC undergoing formal surgery had a reduced risk of allcause mortality compared with those treated by local excision only. However, this was not explained by a reduced risk of recurrence/disease-free survival or CRC death, and suggests 
that the observed benefits may simply reflect selection of a healthier patient population in the formal surgery group. 


\section{Introduction}

Colorectal cancer (CRC) is the fourth most common cancer in the UK (2014), accounting for $12 \%$ of all new cases and is the third most common cancer in both males and females. ${ }^{1}$ Of all CRCs diagnosed in the UK in 2014, the National Bowel Cancer Audit found that $6.2 \%$ were stage $\mathrm{pT} 1 .^{2}$ The management of $\mathrm{pT} 1 \mathrm{CRC}$ remains controversial despite much debate. With the introduction of screening, the number of early stage CRC has risen, particularly the number of malignant polyps removed endoscopically. ${ }^{3}$

Endoscopic resection of such early stage tumours, with appropriate endoscopic follow-up, may be sufficient to prevent disease progression, depending on favorable pathological features within the local excision specimen. ${ }^{4}$ Alternatively, patients can be referred for formal colorectal resection, which may remove any residual invasive disease in tissue surrounding the polypectomy site or in regional lymph nodes, in an attempt to reduce the risk of local or distant recurrence. Removal of lymph nodes will improve staging and inform the need for adjuvant chemotherapy.

Local excision is associated with low morbidity and post-operative mortality in comparison to elective surgery, for which mortality in the UK has been reported as $2.3 \% .^{2}$ Surgical risk adjustment models such as the Association of Coloproctology of Great Britain and Ireland (ACPGBI) Mortality Model, which is specific to CRC patients, and the CR-POSSUM model which is applicable to all colorectal surgical procedures, have shown co-morbidities and age to be of importance in determining survival. ${ }^{5,6}$

Local excision however, does not allow evaluation of lymph node status, thus the potential for adjuvant therapy is lost among patients generally assumed to be node negative. For pT1 
CRC the risk of lymph node metastases is reported to be between $8-16 \%$, suggesting the need for a more precise method in the prediction of lymph node metastasis. ${ }^{7,8}$ The identification of adverse histopathological features may help predict lymph node metastatic disease, features including lymphovascular invasion (LVI), tumour differentiation or grade, Haggitt or Kikuchi level and, more recently, tumour budding and depth and width of submucosal invasion. ${ }^{8,9}$ The absence of adverse histological features supports a conservative management strategy of local excision, with one study observing almost no risk of recurrence among those without any such surgical indictations. ${ }^{10}$

Population-based data estimating the risk of recurrence or death in patients following a stage pT1 CRC diagnosis are sparse. Recent data from a large US SEER study, comparing local excision with neoadjuvant therapy and surgery, observed similar clinical outcomes for T1 rectal cancer, but not for colon cancer. ${ }^{11}$ The authors were unable to evaluate recurrence and lacked potential confounding factors such as tumour pathological features. Contrastingly, another US study observed a higher incidence of local recurrence among pT1 CRC patients after local or endoscopic resection in comparison to radical resection, ${ }^{12}$ however there is limited generalisability to UK populations.

The aim of the proposed population-based study is to evaluate patient management following a stage PT1 CRC diagnosis, and to determine the risk of cancer progression (local or distant recurrence, metastases or death) following treatment. 


\section{Method}

\section{Study design}

The Northern Ireland Cancer Registry (NICR) collects information on all cancer cases within Northern Ireland (population 1.8 million), which have been diagnosed since 1993 . The NICR contains information on patient demographics such as sex, age at diagnosis, as well as cancer site, stage and year of diagnosis. From the NICR individuals with a CRC diagnosis, staged as pT1 between 2007 and 2012 were identified. Cases of pT1 staged CRC diagnosed prior to 2007 were not included due to changes in TNM classifications at this time. Matching to the Northern Ireland Bowel Cancer Screening Programme pathology database facilitated the identification of screen-detected tumours. Bowel cancer screening was introduced in Northern Ireland from June 2010, and was fully rolled out by 2012.

The NICR has access via electronic download to all historical pathology reports. From these reports, using a standard proforma, available information on clinical and pathological tumour characteristics was recorded including grade (worst), Haggitt level (1-4 or not applicable[n/a]), Kikuchi level (SM1-3 or n/a), lymphovascular invasion (yes, no, suspicious or $\mathrm{n} / \mathrm{a}$ ) and, for those undergoing surgical resection, extramural vascular invasion (EMVI) and lymph node involvement. Pathology slide review was not performed. Information on patient management was determined from the electronic Clinical Oncology Information System (COIS) and from electronic pathology reports. COIS is an electronic data recording system, used in all cancer units in Northern Ireland, which includes annotated notes recorded by clinicians from each oncology visit after a cancer diagnosis, giving information on stage, 
treatments received, investigations undertaken. COIS also contains information on previous medical history and demographic and lifestyle information, from which we recorded data on comorbidities (including respiratory disease, cardiac disease and diabetes). COIS captures data on all patients seen at an oncology department within Northern Ireland i.e. only patients being considered for adjuvant therapies had their details recorded in COIS. Both COIS and electronic pathology reports were used to determine if patients were treated by local excision only (polypectomy, endoscopic mucosal resection or transanal endoscopic microsurgery) or by surgical resection. Information on local resection margins was also recorded based on the residual tumour classification (R0,R1 or R2) , Finally, information on adjuvant chemotherapy receipt was also recorded from COIS.

Approval for the study was granted under the generic ethics of the Northern Ireland Cancer Registry given by ORECNI (REC: 10/NIR02/53), following local approval for the study from clinicians at the Colorectal Cancer meeting of the Northern Ireland Cancer Network.

\section{Case Selection}

531 individuals were recorded as having a stage pT1 CRC diagnosis (Figure 1). Exclusion criteria applied to this sample included: cancer recorded as a higher stage (T2/T3/T4) on COIS or after subsequent resection $(n=32)$, being aged less than 30 years $(n=2)$, having a synchronous tumour staged higher than pT1 $(n=16)$, having metastatic disease at diagnosis $(n=16)$, carcinoid $(n=16)$ or low grade mucinous neoplasms (LAMN) $(n=2)$, a previous history of CRC $(n=12)$, no electronic pathology report being available for review $(n=21)$, inability to determine type of treatment procedure undergone $(n=1)$, received neoadjuvant 
radiotherapy $(n=7)$ or underwent biopsy only $(n=12)$. The remaining $n=394$ pT1 CRC cases were included in our analysis.

\section{Outcomes}

Cancer recurrence, defined as 1) local, 2) distant or 3) local and distant metachronous or metastatic tumour, was determined from COIS. Death information was obtained through linkage to Northern Ireland General Registrar Office for deaths occurring by $31^{\text {st }}$ October 2015. Deaths were classified as CRC-specific if CRC was recorded as the primary underlying cause of death (International Classification of Diseases- C18, C19, C20, C21 or C26). Overall survival and CRC-specific disease free survival (defined broadly as any recurrence, local or distant, or death from CRC during the follow-up period [i.e. from pT1 CRC diagnosis through to $31^{\text {st }}$ October 2015]) were also investigated.

\section{Statistical analysis}

Patient characteristics and pT1 tumour pathological characteristics were compared between those who underwent surgery and those who did not, using chi-squared or ANOVA tests. Survival analysis was conducted using Cox proportional hazard models to calculate hazard ratios $(\mathrm{HR})$ and $95 \%$ confidence intervals $(95 \% \mathrm{Cl})$ for cancer-specific and all-cause mortality, comparing formal surgery and local excision treatment procedures. Logistic regression models were used to calculate odds ratios $(\mathrm{OR})$ and $95 \% \mathrm{Cl}$ for associations with cancer recurrence and disease-free survival due to uncertainty of exact date of recurrence. Analyses were conducted adjusting for age and sex, tumour grade, LVI status, co-morbidities and screen-detected cancers. Sensitivity analyses excluding tumours with positive nodal status or 
patients who received adjuvant chemotherapy, and stratified analysis by pT1 tumour site (colon/rectum) were also conducted. 


\section{Results}

A total of 394 patients diagnosed with pT1 CRC were retained in the analytical cohort, in which 60 deaths (including 10 CRC-specific deaths) occurred over a mean 4.8 (range 0.1-8.8) years of follow-up. A further 12 individuals had a metachronous recurrence but were still alive at the end of follow-up, therefore 22 individuals were classified as having a CRC-specific death or recurrence.

\section{Treatment characteristics}

As outlined in Table 1, 146 patients (37.1\%) had a local excision only, 145 patients underwent surgical resection only and 103 patients continued to surgical resection following a local excision. The majority of local excisions were polypectomies, either intact or piecemeal. Within this group, 7.6\% did not achieve clear margins. As expected, patients undergoing local excision only were more likely to have clear margins than patients undergoing local excision followed by surgery ( 86.3 v. $70 \%, P<0.001)$. In patients undergoing surgical resection, the most common procedures were sigmoid colectomy (32\%), anterior resection $(25.7 \%)$ or right hemicolectomy (21.7\%). Eighteen patients received adjuvant chemotherapy, of whom two later died from CRC. As shown in Figure 2, the proportion of patients undergoing only a local excision was smaller amongst those who later had a CRC-specific death or recurrence (27.3\%), but was greater amongst patients who died from any cause (53.3\%). 
Patient characteristics by treatment received

As shown in Table 2, the number of PT1 CRC diagnosed has increased over the six-year timeframe, however there were no differences in clinical management by local excision or surgical resection over time $(P=0.97)$. The majority of pT1 CRC patients were aged $>60$ years old $(81.7 \%)$, and significantly fewer patients within these older age groups underwent surgery compared with local excision only $(P<0.01)$. There were no differences in sex, tumour location or reported co-morbidities between patients undergoing different treatments. A small proportion (3.6\%) of patients had a noted family history of CRC, and these patients were more likely to undergo formal surgery either as an initial treatment or following local excision $(P=0.04)$. Twelve percent of $\mathrm{pT} 1$ cancers were screen-detected and these tumours were more likely to be treated by local excision than undergo formal surgery only $(P=0.01)$.

Tumour characteristics by treatment received

Those cancers within local excision specimens which subsequently underwent surgery demonstrated higher proportions of cases, compared to those treated by local excision alone, for each of the recognised adverse features traditionally considered indications for surgery, namely poor differentiation (6.8\% v. $2.7 \%)$, Kikuchi level SM2/3 (19.4\% v. 7.6\%), definite or possible lymphovascular invasion ( $28.1 \%$ v. $13 \%)$ and margin involvement by tumour $(20.4 \%$ v. 6.2\%). Note that only either Haggitt level (pedunculated tumours) or Kikuchi level (sessile tumours) is applicable in each case, never both, and in certain circumstances e.g. piecemeal resection, neither may be assessable, hence the apparently high missing data rate for these parameters. These parameters are often only reported with local excision specimens, not in 
formal surgical resections. Of interest, the nodal involvement rate is higher in those cases diagnosed at surgery, without preceding polypectomy, compared to those with proceding polypectomy ( $12.6 \%$ v. $6.4 \%)$, reflecting more locally advanced, endoscopically unresectable disease in the former group associated with higher risk of regional nodal metastatic disease.

\section{Survival analyses}

Rates of survival outcomes by surgical treatment are detailed in Table 4 and Figure 2. Undergoing a surgical resection (with or without prior local excision) did not reduce the likelihood of a CRC-specific death or recurrence (Figure 3). This association remained nonsignificant upon adjustment for other factors such as age, sex, co-morbidities, tumour grade, LVI status and detection via screening (adjusted $\mathrm{HR}=1.8995 \% \mathrm{Cl} 0.38,9.35$ ). Contrastingly, patients undergoing formal surgery did have a reduced risk of all-cause mortality (adjusted $\mathrm{HR}=0.5495 \% \mathrm{Cl} 0.32,0.92)$ compared with patients undergoing local excision only.

Observed associations were similar when excluding patients with lymph node involvement or those who received adjuvant chemotherapy (Table 4) Overall, associations remained largely similar when stratifying by site (Tables 5 \& 6). However associations no longer remained for formal surgery and all-cause mortality in rectal cancer patients $(\mathrm{HR}=0.4595 \% \mathrm{Cl} 0.22,1.90)$ 


\section{Discussion}

This population-based cohort study analysed patient outcomes following treatment of pT1 colorectal cancer by local excision or formal surgery. The key findings reveal no difference in disease-free survival between the two groups. There was, however, a significant difference in all-cause mortality between the two groups, with reduced mortality in the cohort undergoing formal surgery. Tekkis et al published a large analysis of 43494 patient outcomes following local excision (7378) and major resection (36116) for T0, 1 and 2 colon and rectal cancer. Their findings demonstrated no difference in 5-year cancer specific survival for local excision vs major resection for $\mathrm{T} 1$ colon or rectal cancer. ${ }^{11}$ The recent meta-analysis by Zhou et al comparing local excision and radical resection for T1 rectal cancer also demonstrated similar findings with no difference in disease-free survival rates. ${ }^{13}$

The observed difference in overall mortality may reflect increased patient frailty and comorbidities in the older age groups therefore leading to patient selection bias. Although we did adjust for a number of important co-morbidities, these were limited in number, thus residual confounding by unmeasured comorbidities remains possible. Our study revealed significantly fewer patients over age 80 years having a surgery compared to younger patients, and a combination of patient choice and increased frailty in this cohort is likely to account for this. Tekkis et al also observed a reduction in overall survival in the local excision group and concluded as we do that increased patient frailty likely contributed to mortality. ${ }^{11}$ This selection bias is common in population-based cohort studies which are not randomised. 
The introduction of CRC screening continues to be an important tool in reducing advanced disease at time of diagnosis. Early detection rates continue to rise ${ }^{14}$ and the number of pT1 CRCs diagnosed did increase over the timeframe of this study. It was notable that the numbers of patients undergoing local excision did not increase during the study period. This potentially reflects a more conservative approach to the management of CRC in Northern Ireland, although screen-detected T1 tumours were more likely to be treated by local excision than formal surgery.

Almost $10 \%$ of patients undergoing formal resection had tumour involvement of lymph nodes, but no adverse effect in terms of local recurrence or disease-free survival was noted in the local excision group where nodes were not sampled. Lymph node involvement by tumour is less likely in this group, many patients being selected for local excision only by the absence of adverse histology features.

A recent study in France concluded outcomes following polypectomy for malignant polyps with pathological margin $\geq 1 \mathrm{~mm}$ were similar to those following surgery. ${ }^{17}$ Lopez et al found no significant difference in recurrence or survival provided the margin was $>1 \mathrm{~mm}$ for sessile or pedunculated malignant polyps. ${ }^{17}$ Their results in line with our own, confirm that many patients can be treated without the need for major surgery.

This study raises the possibility that the type of surgical procedure, either radical or local resection, does not alter the prognosis in terms of CRC-specific death or disease relapse of patients with pT1 tumours. There are a number of proposed models for disease dissemination in $\mathrm{CRC}$, with views ranging from establishment of metastatic lesions at early or late stages of 
the development of the primary tumour. ${ }^{18}$ Our data support the hypothesis that invasion, dissemination and micro-metastatic disease occurs at the earliest possible stage of cancer development (if it does occur) and that this process is independent of the type of surgery used. By supporting this hypothesis, it also proposes that these aggressive pT1 tumors may be driven by an underlying biology which results in dissemination at the first point of disease development. Recent studies in breast cancer have also indicated that early invasion and dissemination may be the most common pathway to metastasis in HER2-driven disease, suggesting that surgery for later stage localized tumors does not reduce rates of metastatic relapse. ${ }^{19-21}$ Additionally, analysis of epigenetic events across 96 CRC tumors confirmed that DNA methylation patterns in matched metastatic tissue most frequently resembles the earliest initiation point of the tumor, in line with our data suggesting that early dissemination is likely in CRC, in the minority of patients in which stage pT1 CRC does metastasize. ${ }^{22,23}$

Stage I currently accounts for approximately $12 \%$ of all staged CRC cases, although within the UK bowel screening population, this increases to approximately $37-42 \%$ of detected CRC. ${ }^{24}$ Data presented here suggests that, in addition to detecting patients with the most aggressive disease earlier, the screening program will identify a subgroup of patients with aggressive disease who will initially be pathologically staged as pT1. This presents a key challenge of how to distinguish patients with aggressive early stage disease with high-risk of metastatic relapse. We have previously identified a poor prognostic group through immuno-histochemical biomarker-based stratification in stage $1 .{ }^{25}$ Given the paucity of molecular understanding of prognostic factors for this increasing stage I population, there is an urgent need for comprehensive profiling in early-stage CRC, similar to the recent call in regards to premalignant disease. ${ }^{26}$ This type of comprehensive profiling will enable the generation of 
biomarker-driven patient classifiers, allowing the selection of patients with the highest risk of relapse to be prioritised for appropriate disease management with/without adjuvant therapy based on a biological understanding of disease.

Our study has several limitations. We had a relatively small sample size of which we only included $75 \%$ of the original staged pT1 cancers for reasons documented in the methods. However, this demonstrates the robustness of our data. Without pathology slide review, we were unable to robustly investigate the pathological features that predict nodal metastatic disease or, in individuals who underwent local resection only, death or recurrence. There was poor recording in pathology reports of some established histological features and the study timeframe predated distinction of lymphatic from venous invasion and routine evaluation of some more recently established features such as tumour "budding" and tumour width of invasion. Information on recurrence was determined from the clinical oncology system, thus capturing those patients that were seen within a clinical oncology unit in Northern Ireland after diagnosis. While the information from the Northern Ireland Cancer Registry has been shown to be have high completeness and accuracy ${ }^{27}$, the use of COIS for identifying colorectal cancer recurrence has not been validated. Moreover, it is likely that we are missing recurrence information for some patients whose treatment was not discussed within these oncology units. We also had limited data on patients' comorbidities, only capturing co-morbidities that had been recorded within COIS, based on a pro forma of a limited number of selected comorbidities. Given this we were unable to calculate a valid comorbidity score (e.g. the Charlson comorbidity score) and some residual confounding due to comorbidities remains possible. 


\section{Conclusion}

Patients who underwent formal surgery for PT1 CRC had better overall survival rates compared with those treated by local excision. However, this was not explained by a reduced risk of recurrence/disease free survival or CRC death, and suggests that the observed benefits may simply reflect selection of a healthier patient population in the surgery group. The advantages of less invasive intervention for early CRC appear to include reduced mortality, morbidity, organ and function preservation but novel techniques to identify higher risk early stage tumours are needed to ensure this subgroup are offered correct treatment. 


\section{Acknowledgements}

The Northern Ireland Cancer Registry is funded by the Public Health Agency. This work uses data provided by patients and collected by the NHS as part of their care and support. Dr Helen Coleman is a co-investigator of the UKCRC Centre of Excellence for Public Health, NI. 


\section{References}

1. Cancer research UK [Internet], http://www.cancerresearchuk.org/healthprofessional/cancer-statistics/incidence, Accessed January 2017.

2. Health and Social Care Information Centre, National Bowel Cancer Audit Annual Report 2015 [Internet]. Available from http://content.digital.nhs.uk/catalogue/PUB19500/nati-clinaudi-bowe-canc-2015.pdf. Accessed January 2017.

3. Williams JG, Pullan RD, Hill J, Horgan PG, Salmo E, Buchanan GN, et al. Colorectal Dis. Management of the malignant colorectal polyp: ACPGBI position statement. 2013;15 Suppl 2:1-38.

4. Bosch SL, Teerenstra S, de Wilt JH, Cunningham C, Nagtegaal ID. Predicting lymph node metastasis in pT1 colorectal cancer: a systematic review of risk factors providing rationale for therapy decisions. Endoscopy. 2013;45(10):827-34.

5. Tekkis PP, Prytherch DR, Kocher HM, Senapati A, Poloniecki JD, Stamatakis JD, et al.

Development of a dedicated risk-adjustment scoring system for colorectal surgery (colorectal POSSUM). Br J Surg. 2004;91:1174-82.

6. National Institute for Health and Care Excellence (NICE), 2011. Colorectal cancer: the diagnosis and management of colorectal cancer. London: NICE.

7. Morris EJA, Taylor EF, Thomas JD, Quirke P, Finan PJ, Coleman MP, et al. Thirty-day postoperative mortality after colorectal cancer surgery in England. Gut. 2011;60(6):806-13

8. Bosch SL, Nagtegaal ID. Predicting lymph node metastasis in pT1 rectal cancer. Recent Results Cancer Res. 2014;203:15-21.

9. Watanabe T, Itabashi M, Shimada Y, Tanaka S, Ito Y, Ajioka Y et al. Japanese Society for Cancer and Rectum (JSCCR) Guidelines 2014 for treatment of colorectal cancer. Int J Clin Oncol. 2015;20(2):207-239. 
10. Yoshii S, Nojima M, Nosho K, Omori S, Kusumi T, Okuda H et al. Factors associated with risk of colorectal cancer recurrence after endoscopic resection of T1 tumours. Clin Gastroenterol Hepatol. 2014;12(2):292-302.

11. Bhangu A, Brown G, Nicholls RJ, Wong J, Darzi A and Tekkis P. Survival Outcome of Local Excision versus Radical Resection of Colon or Rectal Carcinoma. Annals of Surgery 2013; 258(4):563-571.

12. Kogler P, Kafka-Ritsch R, Ofner D, Sieb M, Augustin F, Pratschke J, et al. Is limited surgery justified in the treatment of T1 colorectal cancer? Surg Endosc. 2013;27(3):817-25.

13. Jun-Yang LU, Geo-Le Lin, Hui-Zhong Qui, Yi Xiao, Bin Wu and Jiao-Lin Zhou. Comparison of Transanal Endoscopic Microsurgery and Total Mesorectal Excision in the treatment of T1 Rectal cancer: A Meta-Analysis PLoS One. 2015; 10(10): e0141427.

14. Results of the first round of a demonstration pilot of screening for colorectal cancer in the United Kingdom. BMJ 2004;329(7458): 133.

15. Haggitt RC, Glotzbach RE, Soffer EE, Wruble LD. Prognostic factors in colorectal carcinomas arising in adenomas: implications for lesions removed by endoscopic polypectomy. Gastroenterology 1985; 89: 328-336.

16. Kikuchi R, Takano M, Takagi K, Fujimoto N, Nozaki R, Fujiyoshi T et al. Management of early invasive colorectal cancer. Risk of recurrence and clinical guidelines. Dis Colon Rectum 1995; 38: 1286-1295.

17. Lopez A, Bouvier A, Jooste V, Cottet V, Romain G, Faivre J et al. Outcomes following poylpectomy for malignant colorectal polyps are similar to those following surgery in the general population. Gut 2019; 68(1):111-117.

18. Naxerova K, Jain RK. Using tumour phylogenetics to identify the roots of metastasis in humans. Nat Rev Clin Oncol 2015;12(5):258-272. 
19. Hosseini H, Obradovic M, Hoffmann M, Harper K, Sosa M, Werner-Klein M et al. Early dissemination seeds metastasis in breast cancer. Nature. 2016; 540 (552-558).

20. Harper K, Sosa M, Entenberg D, Hosseini H, Cheung J, Nobre R et al. Mechanism of early dissemination and metastasis in Her2+ mammary cancer. Nature. 2016; 540 (588-592).

21. Ghajar C, Bissell M. Metastasis: Pathways of parallel progression. Nature. 2016; 540 (528529).

22. Martinez-Cardus A, Moran S, Musulen E, Moutinho C, Manzano J, Martinez-Balibrea E et al. Epigenetic homogeneity within colorectal tumours predicts shorter replase-free and overall survival times for patients with locoregional cancer. Gastroenterology. 2015; 151 (961972).

23.Dunne P, Lawler M. Intratumoural epigenetic heterogeneity in early invasive colorectal cancer: a prognostic imprint? Gastroenterology. 2017; 152 (1622-1623).

24.Logan RFA, Patnick J, Nickerson C, on behalf of the English Bowel Cancer Screening Evaluation Committee, et al. Outcomes of the Bowel Cancer Screening Programme (BSCP) in England after the first 1 million tests. GUT 2012; 61 (1439-1446).

25. Ong CW, Chong PY, McArt DG, Chan JY, Tan HT, Kumar AP, et al. The prognostic value of the stem-like group in colorectal cancer using a panel of immunohistochemistry markers. Oncotarget 2015;6(14):12763-12773.

26. Campbell JD, Mazzilli SA, Reid ME, Dhillon SS, Platero S, Beane J, et al. The Case for a PreCancer Genome Atlas (PCGA). Cancer Prev Res (Phila) 2016;9(2):119-124.

27. Kearney TM, Donnelly C, Kelly JM, O'Callaghan EP, Fox CR, Gavin A. Validation of completeness and accuracy of the Northern Ireland Cancer Registry. Cancer Epidemiol. 2015 ;39(3):401-4. 
Table 1. Treatment received for stage pT1 colorectal cancer in cases diagnosed in Northern Ireland, 2007-2012.

\begin{tabular}{ll}
\hline Treatment & $\begin{array}{l}\text { Overall } \\
\mathbf{N}=\mathbf{3 9 4}(\boldsymbol{\%})\end{array}$ \\
\hline Local excision only & $146(37.1)$ \\
Surgical resection only & $145(36.8)$ \\
Local excision and surgical resection & $103(26.1)$ \\
& \\
Local excision only details & \\
Local excision type* & \\
Polypectomy (intact) & $126(86.3)$ \\
Polypectomy (piecemeal) & $9(6.2)$ \\
Endoscopic mucosal resection & $6(4.1)$
\end{tabular}


Local excision followed by surgical excision details

Local excision type

Polypectomy (intact)

Polypectomy (piecemeal)

Endoscopic mucosal resection

$7(6.8)$

Transanal endoscopic microsurgery

$<5$

\section{Formal surgical resection details}

Surgical resection type*

Right hemicolectomy

$54(21.7)$

Left hemicolectomy

$18(7.2)$

Sigmoid colectomy

$81(32.5)$

Anterior resection

$64(25.7)$

Abdominoperineal resection of rectum

$8(3.2)$

Other

\section{Other treatments received}

*Percentages of local excision type and surgical resection type represent percentages of those undergoing local excision and surgical resection, respectively, rather than the overall 394 individuals. Local excision type was unknown for $<5$ individuals and surgical resection type was unknown for 10 individuals. 
Table 2. Patient characteristics of pT1 colorectal cancer cases diagnosed in Northern Ireland, 2007-2012, stratified by treatment received.

\begin{tabular}{|c|c|c|c|c|c|}
\hline Characteristic & $\begin{array}{l}\text { Overall } \\
n=394 \\
(\%)\end{array}$ & $\begin{array}{l}\text { Local } \\
\text { excision only } \\
n=146(\%)\end{array}$ & $\begin{array}{l}\text { Formal } \\
\text { Surgery } \\
\text { only } \\
(n=145)\end{array}$ & $\begin{array}{l}\text { Local } \\
\text { excision } \\
\& \\
\text { formal } \\
\text { surgery } \\
(n=103) \\
\end{array}$ & $\begin{array}{l}P \text { - } \\
\text { valu } \\
\text { e }\end{array}$ \\
\hline \multicolumn{6}{|l|}{ Year of diagnosis } \\
\hline 2007 & $40(10.2)$ & $16(11.0)$ & $14(9.7)$ & $10(9.7)$ & \\
\hline 2008 & $51(12.9)$ & $19(13.0)$ & $19(13.1)$ & $13(12.6)$ & \\
\hline 2009 & $57(14.5)$ & $20(13.7)$ & $24(16.6)$ & $13(12.6)$ & \\
\hline 2010 & $61(15.5)$ & $20(13.7)$ & $24(16.6)$ & $17(16.5)$ & \\
\hline 2011 & $86(21.8)$ & $32(21.9)$ & $31(21.4)$ & $23(22.3)$ & \\
\hline 2012 & $99(25.1)$ & $39(26.7)$ & $33(22.8)$ & $27(26.2)$ & 0.99 \\
\hline \multicolumn{6}{|l|}{ Age at diagnosis, years } \\
\hline$<50$ & $27(6.9)$ & $6(4.1)$ & $7(4.8)$ & $14(13.6)$ & \\
\hline $50-59$ & $45(11.4)$ & $9(6.2)$ & $14(9.7)$ & $22(21.4)$ & \\
\hline $60-69$ & 136 & $57(39.0)$ & $48(33.1)$ & $31(30.1)$ & \\
\hline $70-79$ & $(34.5)$ & $53(36.2)$ & $59(40.7)$ & $30(29.1)$ & \\
\hline$\geq 80$ & $\begin{array}{l}142 \\
(36.0) \\
44(11.2)\end{array}$ & $21(14.4)$ & $17(11.7)$ & $6(5.8)$ & $\begin{array}{l}<0.0 \\
1\end{array}$ \\
\hline \multicolumn{6}{|l|}{ Sex } \\
\hline Male & 221 & $87(59.6)$ & $79(54.5)$ & $55(53.4)$ & \\
\hline Female & $\begin{array}{l}(56.1) \\
173 \\
(43.9)\end{array}$ & $59(40.4)$ & $66(45.5)$ & $48(46.6)$ & 0.55 \\
\hline \multicolumn{6}{|l|}{ Site } \\
\hline Colon & 263 & $96(65.8)$ & $102(70.3)$ & $65(63.1)$ & \\
\hline $\begin{array}{l}\text { Rectum/Rectosigmoid } \\
\text { junction }\end{array}$ & $\begin{array}{l}(66.8) \\
131 \\
(33.3)\end{array}$ & $50(34.3)$ & $43(29.7)$ & $38(36.9)$ & 0.47 \\
\hline \multicolumn{6}{|l|}{ Family history of CRC } \\
\hline Yes & $14(3.6)$ & $<5$ & $9(6.2)$ & $<5$ & \\
\hline No/Unknown & $\begin{array}{l}380 \\
(96.5)\end{array}$ & $145(99.3)$ & $136(93.8)$ & $99(96.1)$ & 0.04 \\
\hline \multicolumn{6}{|c|}{ Any recorded comorbidity* } \\
\hline Yes & $23(5.8)$ & $9(6.2)$ & $9(6.2)$ & $5(4.9)$ & \\
\hline No/unknown & $\begin{array}{l}371 \\
(94.2)\end{array}$ & $137(93.8)$ & $136(93.8)$ & $98(95.2)$ & 0.88 \\
\hline \multicolumn{6}{|l|}{ Screen-detected CRC } \\
\hline Yes & $49(12.4)$ & $25(17.1)$ & $9(6.2)$ & $15(14.6)$ & \\
\hline No & $\begin{array}{l}345 \\
(87.6)\end{array}$ & $121(82.9)$ & $136(93.8)$ & $88(85.4)$ & 0.01 \\
\hline
\end{tabular}

CRC: Colorectal cancer. Percentages may not total $100 \%$ due to rounding.

*Includes any long-term co-morbid condition noted in patient records (from COIS), such as asthma, diabetes, autoimmune diseases, cardiovascular

diseases, hypertension, dementia etc. 
Table 3. Tumour pathological characteristics of pT1 colorectal cancer cases diagnosed in Northern Ireland, 2007-2012, stratified by treatment received.

\begin{tabular}{|c|c|c|c|c|c|}
\hline Characteristic & $\begin{array}{l}\text { Overall } \\
(n=394)\end{array}$ & $\begin{array}{l}\text { Local } \\
\text { excision only } \\
(n=146)\end{array}$ & $\begin{array}{l}\text { Formal } \\
\text { Surgery only } \\
(n=145)\end{array}$ & $\begin{array}{l}\text { Local excision } \\
\text { \& formal } \\
\text { surgery } \\
(n=103)\end{array}$ & P value \\
\hline \multicolumn{6}{|l|}{ Differentiation Grade } \\
\hline Well/Moderate & $316(80.2)$ & $112(76.7)$ & $127(87.5)$ & $77(74.8)$ & \\
\hline Poor & $25(6.4)$ & $<5(2.7)$ & $14(9.7)$ & $7(6.8)$ & \\
\hline Unknown & $53(13.5)$ & $30(20.6)$ & $<5$ & $19(18.5)$ & $<0.001$ \\
\hline \multicolumn{6}{|l|}{ Haggitt level } \\
\hline 1 & $41(10.4)$ & $34(23.3)$ & $<5$ & $<5$ & \\
\hline 2 & $37(9.4)$ & $21(14.4)$ & $<5$ & $12(11.7)$ & \\
\hline $3-4$ & $64(16.2)$ & $33(22.6)$ & $6(4.2)$ & $25(24.3)$ & \\
\hline Not applicable/not stated & $252(64.0)$ & $58(39.7)$ & $131(90.3)$ & $63(61.2)$ & $<0.001$ \\
\hline \multicolumn{6}{|l|}{ Kikuchi level } \\
\hline SM1 & $17(4.3)$ & $12(8.2)$ & $<5$ & $<5$ & \\
\hline SM2-SM3 & $36(9.1)$ & $11(7.6)$ & $<5$ & $20(19.4)$ & \\
\hline Not applicable/not stated & $341(86.6)$ & $123(84.2)$ & $138(95.2)$ & $80(77.7)$ & $<0.001$ \\
\hline \multicolumn{6}{|l|}{ Lymphovascular invasion } \\
\hline No & $239(60.7)$ & $106(72.6)$ & $75(51.2)$ & $58(56.3)$ & \\
\hline Yes & $55(14.0)$ & $12(8.9)$ & $29(20.0)$ & $13(12.6)$ & \\
\hline Possible/suspicious & $22(5.6)$ & $6(4.1)$ & $0(0.0)$ & $16(15.5)$ & \\
\hline Unknown/ not stated & $78(19.8)$ & $21(14.4)$ & $41(28.3)$ & $16(15.3)$ & $<0.001$ \\
\hline Extramural venous invasion & - & - & $<5$ & 0 & \\
\hline Lymph node involvement & - & - & $18(12.6)$ & $6(6.4)$ & 0.284 \\
\hline \multicolumn{6}{|l|}{ Local excision margin status } \\
\hline R1/R2 & $30(7.7)$ & $9(6.2)$ & & $21(20.4)$ & $<0.001$ \\
\hline
\end{tabular}

Percentages may not total $100 \%$ due to rounding. 
Table 4. The association between treatment received and survival outcomes in pT1 colorectal cancer cases diagnosed in Northern Ireland, 20072012.

\begin{tabular}{|c|c|c|c|c|c|c|}
\hline & $\begin{array}{l}\text { Deaths/ } \\
\text { recurrenc } \\
\text { e }\end{array}$ & $\begin{array}{l}\text { Alive/No } \\
\text { recurrenc } \\
\mathrm{e}\end{array}$ & $\begin{array}{l}\text { Unadjusted } \\
\text { HR/ OR } \\
(95 \% \text { CI })\end{array}$ & $P$ value & $\begin{array}{l}\text { Adjusted* } \\
\text { HR/OR }(95 \% \text { CI })\end{array}$ & $P$ value \\
\hline \multicolumn{7}{|l|}{ Colorectal cancer-specific mortality } \\
\hline Local excision only & $<5$ & 144 & 1.00 & & 1.00 & \\
\hline Formal surgery** & 8 & 240 & $2.22(0.47,10.43)$ & 0.31 & $1.89(0.38,9.35)$ & 0.43 \\
\hline Formal surgery, excluding node positive & 6 & 218 & $1.84(0.37,9.12)$ & 0.47 & $2.26(0.42,12.14)$ & 0.34 \\
\hline $\begin{array}{l}\text { Formal surgery, excluding adjuvant } \\
\text { chemo }\end{array}$ & 6 & 225 & $1.79(0.36,8.87)$ & 0.48 & $2.05(0.39,10.63)$ & 0.39 \\
\hline \multicolumn{7}{|l|}{ Recurrence/disease free survival } \\
\hline Local excision only & 6 & 140 & 1.00 & & 1.00 & \\
\hline Formal surgery** & 16 & 232 & $1.61(0.62,4.21)$ & 0.33 & $1.71(0.61,4.83)$ & 0.31 \\
\hline Formal surgery, excluding node positive & 13 & 211 & $1.44(0.53,3.87)$ & 0.47 & $1.96(0.66,5.86)$ & 0.23 \\
\hline $\begin{array}{l}\text { Formal surgery, excluding adjuvant } \\
\text { chemo }\end{array}$ & 14 & 217 & $1.51(0.57,4.01)$ & 0.41 & $2.30(0.75,7.01)$ & 0.14 \\
\hline \multicolumn{7}{|l|}{ All-cause mortality } \\
\hline Local excision only & 32 & 114 & 1.00 & & & \\
\hline Formal surgery $* *$ & 28 & 220 & $0.48(0.29,0.81)$ & 0.006 & $0.54(0.32,0.92)$ & 0.02 \\
\hline Formal surgery, excluding node positive & 25 & 199 & $0.48(0.28,0.81)$ & 0.006 & $0.60(0.35,1.03)$ & 0.07 \\
\hline $\begin{array}{l}\text { Formal surgery, excluding adjuvant } \\
\text { chemo }\end{array}$ & 25 & 206 & $0.47(0.28,0.79)$ & 0.004 & $0.53(0.31,0.92)$ & 0.02 \\
\hline
\end{tabular}

*Adjusted for sex, age at diagnosis (years), grade (well/well-moderate or moderate/ moderate-poor or poor/unknown), lymphovascular invasion (yes/no or unknown), presence of co-morbidities (yes/no or unknown), screen detected tumour (yes/no).

**Includes patients recorded as having local excision and surgical resection. 
Table 5 The association between treatment received and surgical outcomes in pT1 colon cancer cases diagnosed in Northern Ireland, 2007-2012

\begin{tabular}{|c|c|c|c|c|c|c|}
\hline & $\begin{array}{l}\text { Deaths/ } \\
\text { Recurrence }\end{array}$ & $\begin{array}{l}\text { Alive/ } \\
\text { No recurrence } \\
\end{array}$ & $\begin{array}{l}\text { Unadjusted } \\
\text { HR/OR }(95 \% \mathrm{Cl})\end{array}$ & $P$ value & $\begin{array}{l}\text { Adjusted* } \\
\text { HR/OR }(95 \% \mathrm{Cl})\end{array}$ & $P$ value \\
\hline \multicolumn{7}{|l|}{ Colon cancer-specific mortality } \\
\hline Local excision only & $<5$ & 95 & 1.00 & & 1.00 & \\
\hline Formal surgery** & 6 & 161 & $3.21(0.39,26.65)$ & 0.28 & $2.71(0.30,24.35)$ & 0.37 \\
\hline Formal surgery, excluding node positive & $<5$ & 148 & $2.38(0.267,21.31)$ & 0.44 & $2.64(0.26,26.45)$ & 0.41 \\
\hline Formal surgery, excluding adjuvant chemo & $<5$ & 153 & $2.31(0.26,20.67)$ & 0.45 & $3.35(0.31,35.84)$ & 0.45 \\
\hline \multicolumn{7}{|l|}{ Recurrence/disease free survival } \\
\hline Local excision only & $<5$ & 92 & 1.00 & & 1.00 & \\
\hline Formal surgery** & 10 & 157 & $1.47(0.45,4.80)$ & 0.53 & $1.69(0.45,6.37)$ & 0.44 \\
\hline Formal surgery, excluding node positive & 7 & 145 & $1.11(0.33,3.90)$ & 0.87 & $1.86(0.43,8.00)$ & 0.41 \\
\hline Formal surgery, excluding adjuvant chemo & 8 & 149 & $1.24(0.36,4.22)$ & 0.74 & $2.62(0.56,12.33)$ & 0.22 \\
\hline \multicolumn{7}{|l|}{ All-cause mortality } \\
\hline Local excision only & 23 & 73 & 1.00 & & 1.00 & \\
\hline Formal surgery, excluding node positive & 19 & 133 & $0.49(0.264,0.89)$ & 0.02 & $0.59(0.31,1.11)$ & 0.10 \\
\hline Formal surgery, excluding adjuvant chemo & 19 & 138 & $0.47(0.26,0.86)$ & 0.02 & $0.52(0.28,0.97)$ & 0.04 \\
\hline
\end{tabular}

*Adjusted for sex, age at diagnosis (years), grade (well/well-moderate or moderate/ moderate-poor or poor/unknown), lymphovascular invasion (yes/no or unknown), presence of co-morbidities (yes/no or unknown), screen detected tumour (yes/no).

**Includes patients recorded as having local excision and surgical resection. 
Table 6 The association between treatment received and surgical outcomes in pT1 rectal cancer cases diagnosed in Northern Ireland, 2007-2012

\begin{tabular}{|c|c|c|c|c|c|c|}
\hline & $\begin{array}{l}\text { Deaths/ } \\
\text { Recurrenc } \\
\text { e }\end{array}$ & $\begin{array}{l}\text { Alive/No } \\
\text { Recurren } \\
\text { ce }\end{array}$ & $\begin{array}{l}\text { Unadjusted } \\
\text { HR/OR } \\
\text { (95\% CI) }\end{array}$ & $P$ value & $\begin{array}{l}\text { Adjusted* } \\
\text { HR/OR (95\% CI) }\end{array}$ & $P$ value \\
\hline \multicolumn{7}{|l|}{ Rectal cancer-specific mortality } \\
\hline Local excision only & $<5$ & 49 & 1.00 & & 1.00 & \\
\hline Formal surgery $* *$ & $<5$ & 79 & $\begin{array}{l}1.21(0.11 \\
13.33)\end{array}$ & 0.88 & $0.67(0.05,9.33)$ & 0.72 \\
\hline Formal surgery, excluding node positive & $<5$ & 70 & $\begin{array}{l}1.32(0.12 \\
14.56)\end{array}$ & 0.82 & $0.69(0.05,9.54)$ & 0.78 \\
\hline $\begin{array}{l}\text { Formal surgery, excluding adjuvant } \\
\text { chemo }\end{array}$ & $<5$ & 72 & $\begin{array}{l}1.30(0.12, \\
14.34)\end{array}$ & 0.83 & $0.69(0.05,9.54)$ & 0.78 \\
\hline \multicolumn{7}{|l|}{ Recurrence/disease free survival } \\
\hline Local excision only & $<5$ & 48 & 1.00 & & 1.00 & \\
\hline Formal surgery $* *$ & 6 & 75 & $1.92(0.37,9.91)$ & 0.44 & $1.64(0.27,10.14)$ & 0.60 \\
\hline Formal surgery, excluding node positive & 6 & 66 & $\begin{array}{l}2.18(0.42 \\
11.28)\end{array}$ & 0.35 & $2.07(0.31,13.72)$ & 0.45 \\
\hline $\begin{array}{l}\text { Formal surgery, excluding adjuvant } \\
\text { chemo }\end{array}$ & 6 & 68 & $\begin{array}{l}2.12(0.41 \\
10.94)\end{array}$ & 0.37 & $2.07(0.31,13.72)$ & 0.45 \\
\hline \multicolumn{7}{|l|}{ All-cause mortality } \\
\hline Local excision only & 9 & 7 & 1.00 & & 1.00 & \\
\hline Formal surgery $* *$ & 7 & 74 & $0.47(0.18,1.27)$ & 0.14 & $0.45(0.22,1.90)$ & 0.43 \\
\hline Formal surgery, excluding node positive & 6 & 66 & $0.45(0.16,1.26)$ & 0.13 & $0.63(0.21,1.90)$ & 0.41 \\
\hline Formal surgery, excluding adjuvant chemo & 6 & 68 & $0.44(0.16,1.23)$ & 0.18 & $0.63(0.21,1.90)$ & 0.41 \\
\hline
\end{tabular}

*Adjusted for sex, age at diagnosis (years), grade (well/well-moderate or moderate/moderate-poor or poor/unknown), lymphovascular invasion (yes/no or unknown), presence of co-morbidities (yes/no or unknown), screen detected tumour (yes/no).

**Includes patients recorded as having local excision and surgical resection. 
Figure 1. Flow chart outlining patient selection

\section{1 pT1 CRC}

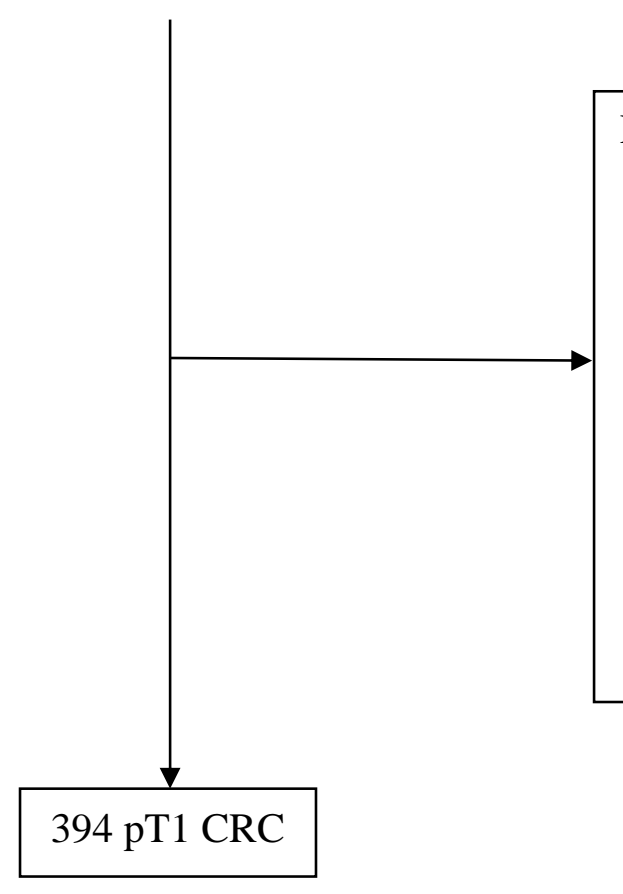

Exclusions:

- Recorded as T2/T3/T4 in COIS/at resection ( $\mathrm{N}=32$ )

- Metastatic disease at diagnosis $(\mathrm{N}=16)$

- Synchronous tumour staged higher than T1 ( $\mathrm{N}=16)$

- Carcinoid tumours ( $\mathrm{N}=16)$

- LAMN tumours ( $\mathrm{N}=2)$

- Patients with a previous history of CRC $(\mathrm{N}=12)$

- < 30 years old ( $\mathrm{N}=2)$

- No electronic pathology report $(\mathrm{N}=21)$

- Inability to determine type of procedure $(\mathrm{N}=1)$

- Neoadjuvant therapy $(\mathrm{N}=7)$

- Biopsy only ( $\mathrm{N}=12)$ 
Figure 2. Proportion of all patients, patients who died or had a recurrence, according to initial treatment received for $\mathrm{pT} 1$ colorectal cancer.

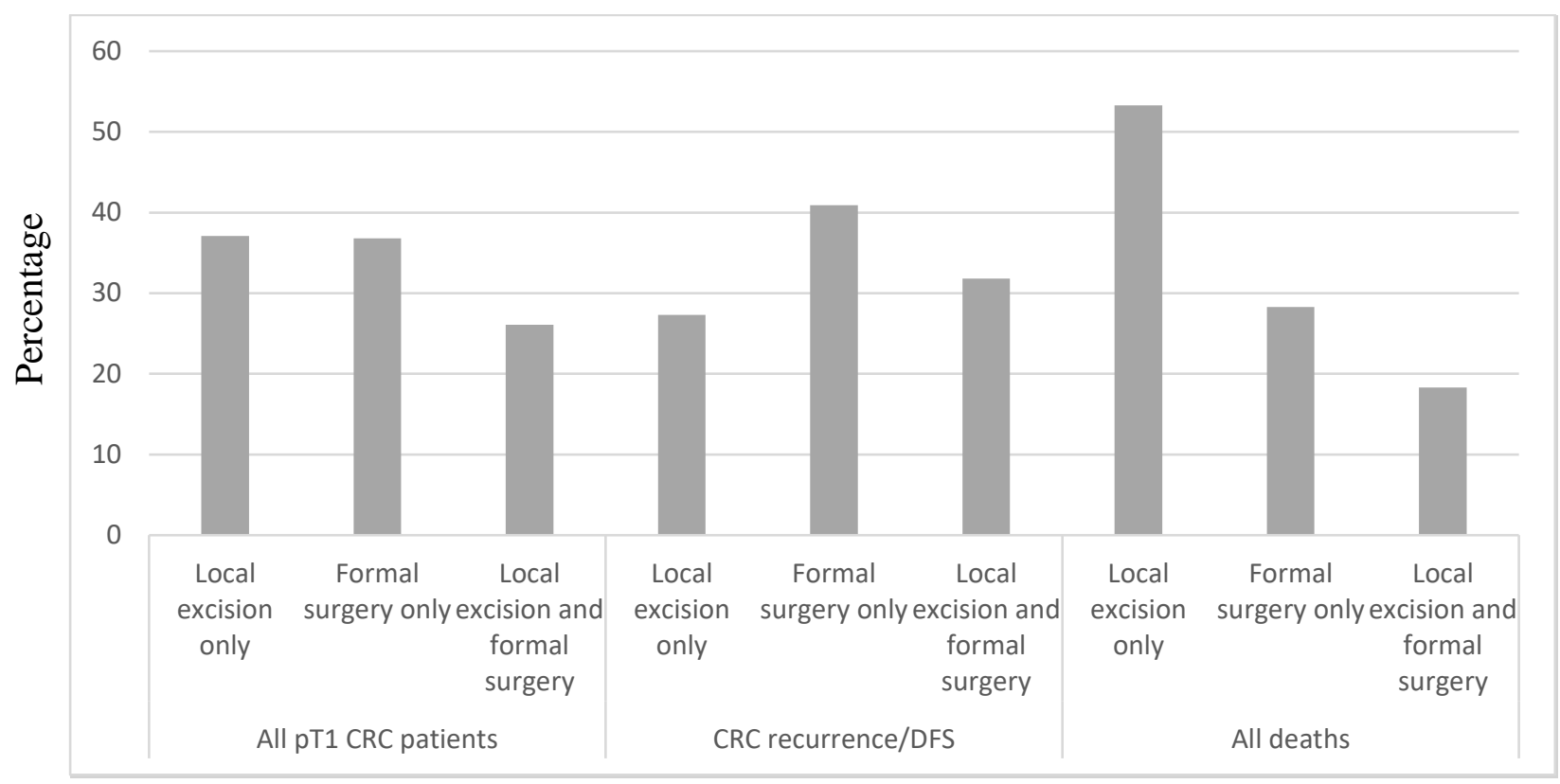

CRC: Colorectal cancer; DFS: Disease-free survival 
Figure 3. Kaplan-Meier curves for survival outcomes comparing patients with pT1 colorectal cancer who underwent local excision or formal surgery.

A. Recurrence/disease free survival

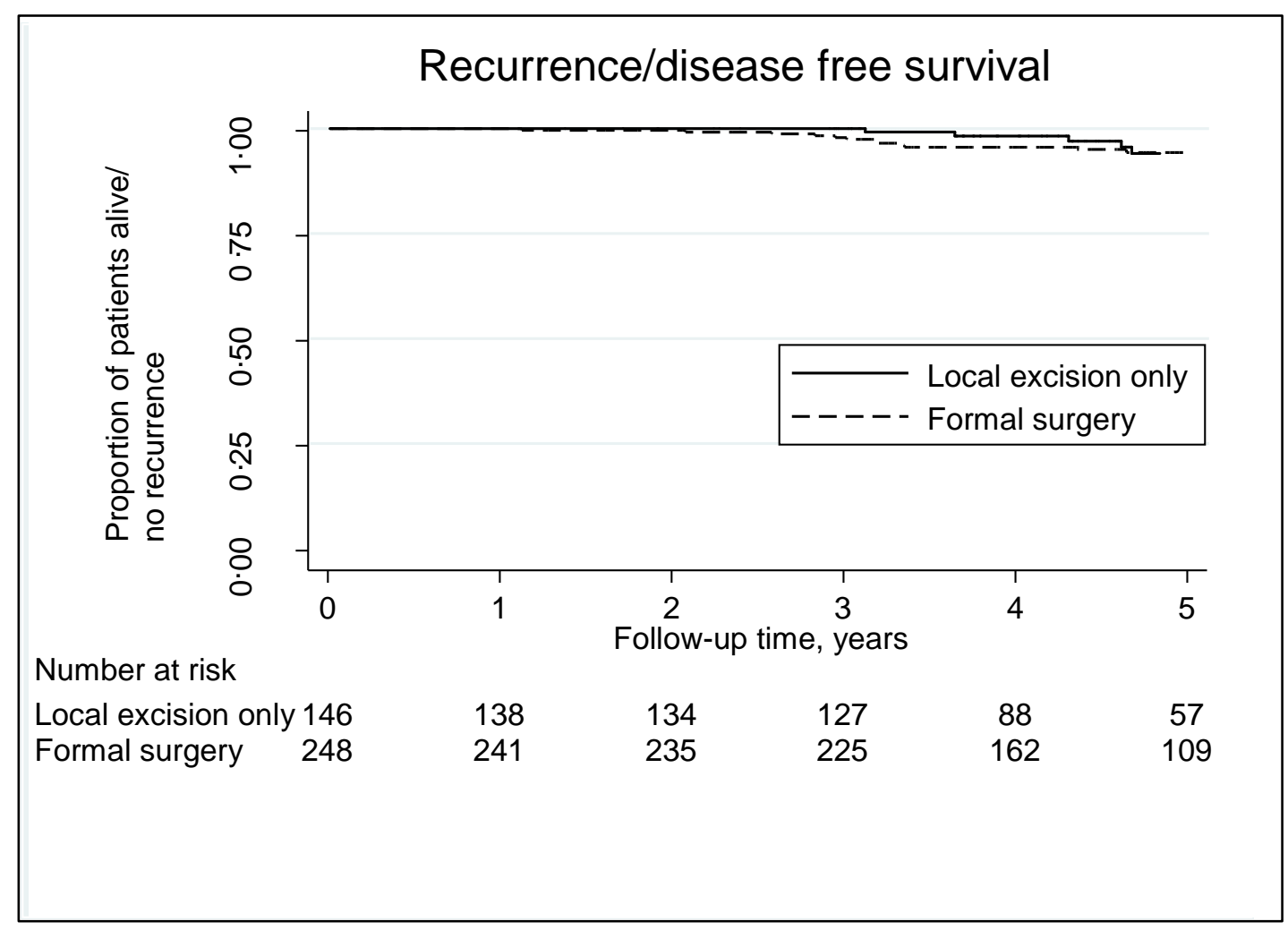

B. Overall survival 


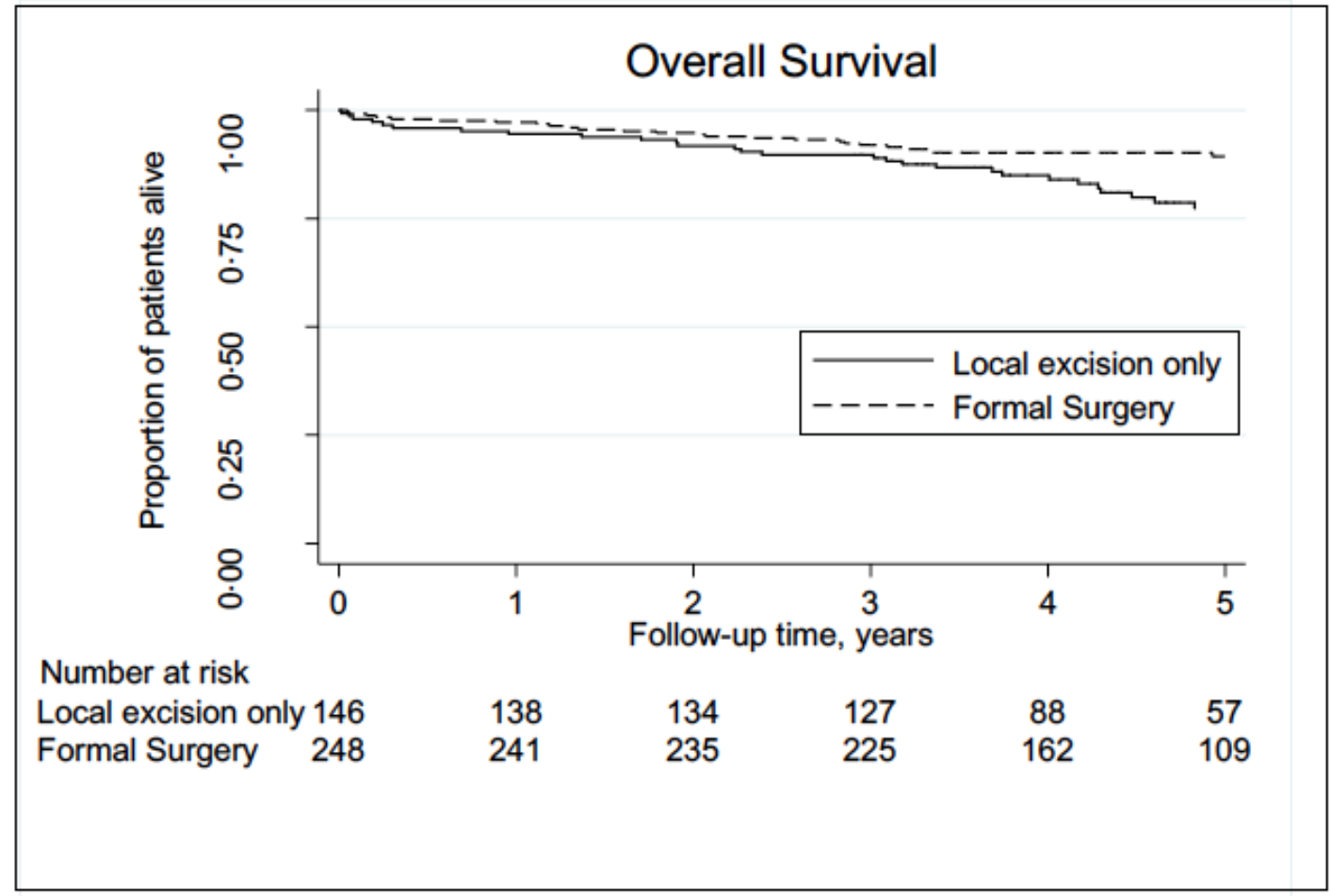

